\title{
Acute Kidney Injury Electronic Alert for Nephrologist: Reactive versus Proactive?
}

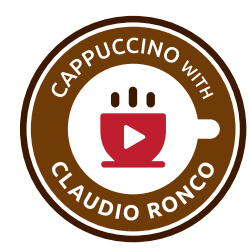

\author{
Kianoush Kashania, b Claudio Ronco ${ }^{c, d}$ \\ ${ }^{a}$ Division of Nephrology and Hypertension, Department of Internal Medicine, and ${ }^{b}$ Division of Pulmonary and \\ Critical Care, Department of Internal Medicine, Mayo Clinic, Rochester, Minn., USA; ' Department of Nephrology \\ Dialysis and Transplantation, San Bortolo Hospital, and d International Renal Research Institute (IRRIV), Vicenza, Italy
}

\author{
Key Words \\ Acute kidney injury · Electronic health records · Nephrology \\ hospital practice
}

\begin{abstract}
Acute kidney injury (AKI) is a common complication of acute illnesses with significant impact on the mortality and morbidity. Early recognition of AKI allows clinicians to provide prophylactic interventions and to improve the outcomes of this deadly syndrome. Growing utilization and capabilities of electronic health records allow AKI risk stratification and early recognition with a potential effect on the processes of care and outcomes. We evaluate the current level of evidence on the impact of the AKI e-alert on the processes of care and outcomes. We then discuss the impacts of e-alerting in the design of the future of nephrology service within the hospital practices with suggestions regarding the role of nephrologists in management of AKI e-alert systems in order to improve the quality of care provided to AKI patients. Video Journal Club 'Cappuccino with Claudio Ronco' at http://www.karger.com/?doi=450722. @ 2016 S. Karger AG, Basel
\end{abstract}

\section{Introduction}

Acute kidney injury (AKI) is one of the most common complications of acute illnesses in intensive care units (ICUs) and hospitals [1-3]. The adverse impacts of AKI on mortality and morbidity have been highlighted in a significant number of modern studies. When critically ill patients develop AKI, they not only have higher mortality and morbidity but also their length of stay (LOS) in the ICU and hospital as well as the associated cost significantly increases $[4,5]$. The clinical and financial burden of this syndrome on the healthcare systems in both developed and developing countries is very large [6]. Unfortunately, despite the gravity of AKI, no treatment has been developed that effectively reverses the injury to the kidney and restores its function. Therefore, preventing development and progression of AKI and management of any subsequent complications are the only available options to avoid the unfavorable outcomes associated with AKI [7]. Risk stratification of critically ill patients and early recognition of AKI are essential in the process of care for critically ill patients [8-10].

In the majority of healthcare institutions, emergency medicine physicians, critical care providers or hospitalists are on the forefront of these tasks. Usually, nephrology services are requested only when AKI has reached advanced stages; hence, the involvement of nephrology in the care of AKI patients is limited to the management of advanced AKI, including providing renal replacement therapies (RRTs) [11]. The emergence of more advanced electronic health records (EHRs) and their ability to identify appropriate patients allow nephrologists to adopt a more proactive role in the prevention and management of AKI.

\section{KARGER}

E-Mail karger@karger.com

www.karger.com/bpu
(C) 2016 S. Karger AG, Basel

0253-5068/16/0424-0323\$39.50/0 
In this article, we review the current level of evidence regarding the importance of early AKI recognition, the role of the EHR in the identification of AKI and also our suggestions relating to changes in the practice of acute nephrology.

\section{Early Recognition}

In the conceptual model of AKI, the Acute Dialysis Quality Initiative investigators suggested AKI to be a process that starts with damage in high-risk individuals and progresses with decreased glomerular filtration rate (GFR), kidney failure and death [12]. As the GFR progressively declines, the possibility of complications, including mortality, continues to rise [13]. Traditional functional biomarkers of AKI, including serum creatinine, cystatin $\mathrm{C}$ and urine output, are inherently unable to detect injurious processes in the kidney during the early phases of damage. This can lead to the late detection of AKI after the therapeutic window for any intervention has significantly narrowed [14]. To avoid such delays in the care of critically ill patients who develop AKI, risk stratification models and biomarkers of early kidney injury have been developed $[15,16]$. Clinical models and novel injury and stress biomarkers of AKI can identify patients while the therapeutic window is more open and the chance of a successful clinical intervention to prevent development and progression of AKI is higher [17].

Prevention of AKI could be provided in 3 distinct timelines. For primary AKI prevention, identification of patients with increased risk of AKI prior to exposure to any injurious agent would be critical. Determining which patients are at high risk would enable clinicians to choose less nephrotoxic strategies in the process of treatment or management of out- or in-patient settings. One example of this type of prevention that was shown to curtail the incidence of AKI was recently published [18]. The authors demonstrated that remote ischemic preconditioning of the kidneys of high-risk patients scheduled for cardiovascular surgery was very effective in avoiding AKI and the need for RRT (absolute risk reduction 15\%, 95\% CI 2.6-27.4, $\mathrm{p}=$ 0.02 ; and absolute risk reduction $10 \%, 95 \%$ CI $2.3-17.8, \mathrm{p}=$ 0.01 , respectively). Following exposure to the injurious process, it is important to identify the existence or extent of injury in order to strategize treatment plans accordingly. An example of a secondary prevention study was reported by Endre et al. [19]. These investigators used a panel of biomarkers to identify patients who had evidence of tubular cell injury in order to provide them with a therapeutic in- tervention. Although this study did not show an improvement in the incidence and outcomes of AKI, this investigation is considered an excellent proof of concept for secondary prevention study designs $[19,20]$. Finally, if AKI does materialize, tertiary prevention is required to avoid associated complications. In this phase, clinicians need to identify risk factors and nephrotoxic processes that should be avoided; this, in turn, should mitigate the chances of AKI recurrence and limit its complications [21]. A recently published study showed that early initiation of RRT using continuous modality among those with AKI stage II could lead to significantly improved outcomes [22].

The main preventive interventions are optimization of effective blood volume, maintaining mean arterial pressure and avoiding nephrotoxins [23], all of which are very time sensitive. Suggested strategies to provide timely preventive measures include, but are not limited to, the use of early biomarkers of stress and injury [24], clinical risk stratification models [25-28], a furosemide stress test [29, $30]$ and use of the renal angina index [31-33].

\section{The Role of the EHR in Early Recognition of AKI}

Following the enactment of the American Recovery and Reinvestment Act and the Health Information Technology for Economic and Clinical Health Act in 2009, the EHR has been increasingly utilized to enhance the quality of care provided to patients in various settings [34]. The meaningful use of information technology incentive programs provided by the Centers for Medicare and Medicaid Services has expedited implementation of the EHR in healthcare systems across the country [35]. The literature on the impact of the EHR on the practice of critical care, and particularly AKI, is unsettled and growing [36]. A majority of studies indicate that electronic systems designed to predict and identify AKI do impact the quality of care for critically ill patients. Most studies show that changes implemented in the process of care as the result of the electronic alert systems were able to improve patient outcomes, including lowering AKI incidence and progression [37-40] and, in some cases, decrease mortality [41]. Other investigators were not able to determine any benefit from the use of the EHR in detection and prevention of AKI [42-44]. The major differences among the results of these studies may be due to the heterogeneity of their designs. Differences in the technology, human factors and methods of delivery can directly impact the EHRs utility in the care of AKI patients. EHRs may differ in their technological complexity and abilities, and the manner in 
which each EHR is used to provide alerts also bears significant importance. The efficacy of EHR-driven alert systems can be affected not only by the way alerts are delivered, for example, to avoid habituation and enhance compliance, but also by concerns over increasing physicians' workload and fatigue [36]. In addition, choosing the appropriate recipient of these alerts and the relevance and accuracy of alarms have an impact on the outcomes [45].

\section{Early Involvement of the Nephrologist}

One of the more relevant factors in this domain is the level of expertise of the alert recipient. For example, Colpaert et al. [39] were able to show improvement in the processes of care when the alert was sent to the intensivists; however, Wilson et al. [44] were not able to replicate this finding when house staff in the ICU and ward received the alerts. Among all the studies included in this review, the majority of alerts were sent to providers who deal with acute illnesses in the ICU or hospital; these included emergency room providers, hospitalists, intensivists or hospital house staff. The alerts were rarely delivered to nephrologists who may be available in the acute care setting. Therefore, the exact impact of such alerts on patient care processes or outcomes when they are delivered to the nephrology teams is not very clear.

On the other hand, the level of evidence to support the early involvement of nephrologists in the care of patients with AKI is very convincing. Mehta et al. [46] in a retrospective study of ICU patients found that nephrology consultation for patients with AKI is delayed by $>48 \mathrm{~h}$ in $28 \%$ of patients, and this, in turn, was associated with higher mortality and ICU/hospital LOS. In another study, Ponce et al. [11] reported that only $52 \%$ of patients with AKI had a nephrology consultation, and in $62 \%$ of the patients, it was delayed $>48 \mathrm{~h}$. Among those with delayed nephrology consultation, the ICU mortality rate was significantly higher ( 65 vs. $88 \%, \mathrm{p}<0.001$ ). Finally, in a recent Brazilian cohort, investigators noted similar results (OR for mortality regardless of the need for dialysis among those with a delayed nephrology consult was 4.04 with 95\% CI 1.65-8.15; OR for dialysis dependence on hospital discharge 3; 95\% CI 1.43-6.29) [47].

Among patients who are not critically ill, non-referral or delayed nephrology referral for AKI was also shown to be significantly associated with the higher need for RRT and in-hospital mortality when patients developed AKI. In this study, authors reported that among 1,572 patients with hospital-acquired AKI, no nephrology referral or late referral (mean of $7.8 \pm 3.4$ vs. $3.6 \pm 1.2$ days for early referral group) was very common (22 and 58\%, respectively). Among those with late nephrology consultation, the absolute risk of the need for RRT was 7\% higher when compared with patients who had early nephrology engagement (number of patients who needed the early involvement of the nephrologist to avoid 1 RRT was 14 patients $(\mathrm{NNT}=14)$ ). In addition, authors found that after adjustments for multiple factors (including age, sex, Charlson Comorbidity Index, medical vs. surgical type, AKI cause and stage, need for RRT), no or late nephrology referral was associated with higher in-hospital mortality and worse renal outcomes [48].

\section{Reactive versus Proactive Nephrology Service}

The structure of nephrology services provided to AKI patients in critical care or hospital settings is highly variable among institutions. This variability could impact the quality of nephrology care provided to acutely ill patients. While in some institutions intensivists provide dialysis for critically ill patients, in other healthcare systems, general nephrologists become engaged with the care of AKI patients only when requested by critical care services. In a few hospitals, a highly specialized critical care nephrology group is responsible for such care. Independent of the core structure for these services, nephrologists are usually engaged when patients have more advanced AKI and generally require initiation of RRT. Although the effect of these different approaches on AKI outcomes is not very clear, it is evident that the impact of earlier nephrology involvement is significant.

With the advances made in the EHR and its growing capacity to identify patients at high risk for AKI or those who are in the initial stages of AKI, it is a moral and ethical obligation to shift nephrology practices from being reactive to becoming proactive. In the reactive team structure, nephrology care providers wait to hear from consulting services and depend on the primary care physicians in the emergency department, ICU or hospital to notify them. As outlined above, delayed referrals in the ICU and hospital setting are very common, and late nephrology consultation results in the higher need for dialysis and can lead to increased mortality (fig. 1a). In a proactive nephrology practice structure, a team of nephrologists monitors all patients in the hospital and critical care setting using the EHR. For patients identified to be at high risk, nephrologists review each case in detail and make recommendations regarding limiting expo- 
Fig. 1. Reactive nephrology team structure (a); proactive nephrology team structure (b). $\mathrm{ED}=$ Emergency department.

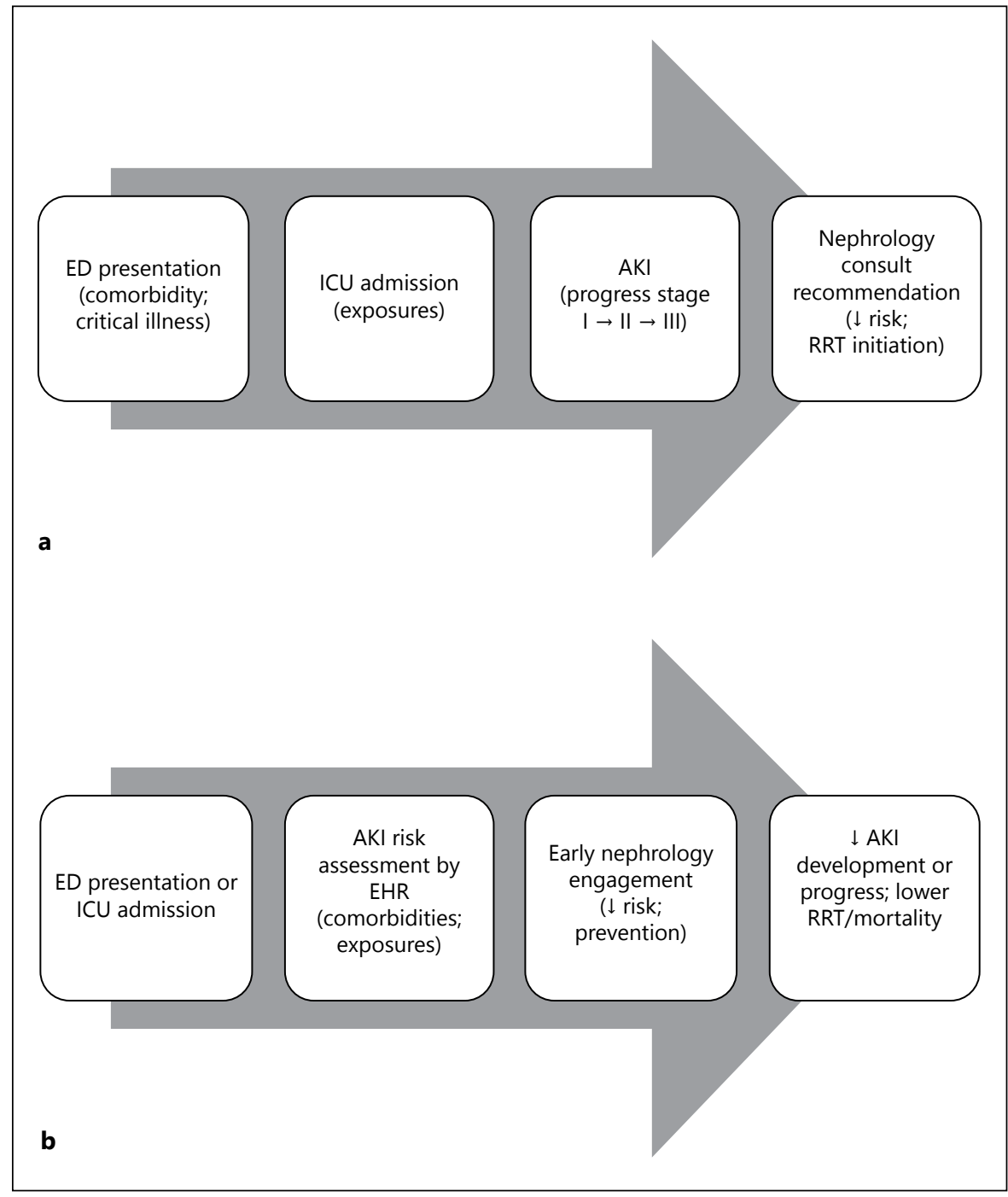

Table 1. Advantages and disadvantages of reactive vs. proactive nephrology team structure

\begin{tabular}{|c|c|c|c|}
\hline \multicolumn{2}{|l|}{ Reactive nephrology practice } & \multicolumn{2}{|l|}{ Proactive nephrology practice } \\
\hline pros & cons & pros & cons \\
\hline $\begin{array}{l}\text { No need for costly change in } \\
\text { current practice }\end{array}$ & Delayed nephrology engagement & Early nephrology engagement & Change of culture \\
\hline \multirow[t]{3}{*}{$\begin{array}{l}\text { Prevention of additional cost of: } \\
\text { - Training staff } \\
\text { - Nephrologist time } \\
\text { - Design and implementation of } \\
\text { EHR-based alerts }\end{array}$} & Increase the need for RRT & Lower need for RRT & $\begin{array}{l}\text { Prevention of additional cost of: } \\
\text { - Training staff } \\
\text { - Nephrologist time } \\
\text { - Design and implementation of } \\
\text { EHR-based alerts }\end{array}$ \\
\hline & Increase in-hospital mortality & Lower in-hospital mortality & \\
\hline & Upstream cost & Downstream cost savings & \\
\hline
\end{tabular}


sures or modifying risks. This results in decreased incidence of AKI development or progression, which translates to less need for RRT and lower in-hospital mortality rates (fig. 1b). This, in turn, has a significant potential to save downstream costs of RRT, prolonged hospital stay and mortality. Either of these approaches carries advantages and disadvantages (table 1). The costs associated with changing the culture of nephrology practice, implementation of the EHR and additional nephrology services could be offset by downstream savings.

\section{Conclusion}

AKI is a grave complication of critical illnesses. Early interventions by providers and, particularly, by nephrologists have been shown to decrease the health and financial burden of AKI. EHRs have the ability to identify patients who are at high risk of AKI or in the early stages of AKI. Redesigning current practices by using the EHR to engage nephrologists early on in the care of AKI patients appears to be the next step in the process to mitigate the impact of AKI on healthcare systems and patients.

\section{Acknowledgments}

None.

\section{Source of Funding}

None.

\section{Disclosure Statement}

None.

\section{Financial Support}

None.

\section{Ethics}

As this article does not include patient recruitment and is a review of current practice and literature along with suggestions regarding the future of Nephrology practice, IRB exempted this manuscript for the review.

\section{References}

1 Siew ED, Davenport A: The growth of acute kidney injury: a rising tide or just closer attention to detail? Kidney Int 2015;87:46-61.

2 O'Connor ME, Kirwan CJ, Pearse RM, Prowle JR: Incidence and associations of acute kidney injury after major abdominal surgery. Intensive Care Med 2016;42:521-530.

3 Susantitaphong P, Cruz DN, Cerda J, Abulfaraj M, Alqahtani F, Koulouridis I, Jaber BL: World incidence of AKI: a meta-analysis. Clin J Am Soc Nephrol 2013;8:1482-1493.

4 Chertow GM, Burdick E, Honour M, Bonventre JV, Bates DW: Acute kidney injury, mortality, length of stay, and costs in hospitalized patients. J Am Soc Nephrol 2005; 16:33653370.

5 Barrantes F, Tian J, Vazquez R, AmoatengAdjepong Y, Manthous CA: Acute kidney injury criteria predict outcomes of critically ill patients. Crit Care Med 2008;36:1397-1403.

6 Lewington AJ, Cerda J, Mehta RL: Raising awareness of acute kidney injury: a global perspective of a silent killer. Kidney Int 2013;84: 457-467.

7 Brochard L, Abroug F, Brenner M, Broccard AF, Danner RL, Ferrer M, Laghi F, Magder S, Papazian L, Pelosi P, Polderman KH; ATS/ ERS/ESICM/SCCM/SRLF Ad Hoc Committee on Acute Renal Failure: An official ATS/ ERS/ESICM/SCCM/SRLF statement: prevention and management of acute renal fail- ure in the ICU patient: an international consensus conference in intensive care medicine. Am J Respir Crit Care Med 2010;181:11281155.

8 Schrier RW: Early intervention in acute kidney injury. Nat Rev Nephrol 2010;6:56-59.

9 Bagshaw SM, Bellomo R: Early diagnosis of acute kidney injury. Curr Opin Crit Care 2007;13:638-644.

10 Coburn S, Mitchell SA: Acute renal failure: early detection and prompt intervention can improve outcomes. Am J Nurs 2002; 102 (suppl 4):6-12; quiz 49-52.

11 Ponce D, Zorzenon Cde P, dos Santos NY, Balbi AL: Early nephrology consultation can have an impact on outcome of acute kidney injury patients. Nephrol Dial Transplant 2011;26:3202-3206.

12 Murray PT, Devarajan P, Levey AS, Eckardt $\mathrm{KU}$, Bonventre JV, Lombardi R, HergetRosenthal S, Levin A: A framework and key research questions in AKI diagnosis and staging in different environments. Clin J Am Soc Nephrol 2008;3:864-868.

13 Himmelfarb J, Joannidis M, Molitoris B, Schietz M, Okusa MD, Warnock D, Laghi F, Goldstein SL, Prielipp R, Parikh CR, Pannu N, Lobo SM, Shah S, D'Intini V, Kellum JA: Evaluation and initial management of acute kidney injury. Clin J Am Soc Nephrol 2008;3: 962-967.
14 Prowle JR, Kolic I, Purdell-Lewis J, Taylor R, Pearse RM, Kirwan CJ: Serum creatinine changes associated with critical illness and detection of persistent renal dysfunction after AKI. Clin J Am Soc Nephrol 2014;9:1015-1023.

15 Kashani K, Al-Khafaji A, Ardiles T, Artigas A, Bagshaw SM, Bell M, Bihorac A, Birkhahn R, Cely CM, Chawla LS, Davison DL, Feldkamp T, Forni LG, Gong MN, Gunnerson KJ, Haase M, Hackett J, Honore PM, Hoste EA, JoannesBoyau O, Joannidis M, Kim P, Koyner JL, Laskowitz DT, Lissauer ME, Marx G, McCullough PA, Mullaney S, Ostermann M, Rimmele T, Shapiro NI, Shaw AD, Shi J, Sprague AM, Vincent JL, Vinsonneau C, Wagner L, Walker MG, Wilkerson RG, Zacharowski K, Kellum JA: Discovery and validation of cell cycle arrest biomarkers in human acute kidney injury. Crit Care 2013;17:R25.

16 Bihorac A, Chawla LS, Shaw AD, Al-Khafaji A, Davison DL, DeMuth GE, Fitzgerald R, Gong MN, Graham DD, Gunnerson K, Heung M, Jortani S, Kleerup E, Koyner JL, Krell K, LeTourneau J, Lissauer M, Miner J, Nguyen HB, Ortega LM, Self WH, Sellman R, Shi J, Straseski J, Szalados JE, Wilber ST, Walker MG, Wilson J, Wunderink R, Zimmerman J, Kellum JA: Validation of cell-cycle arrest biomarkers for acute kidney injury using clinical adjudication. Am J Respir Crit Care Med 2014;189:932-939. 
17 Levin A, Warnock DG, Mehta RL, Kellum JA, Shah SV, Molitoris BA, Ronco C: Improving outcomes from acute kidney injury: report of an initiative. Am J Kidney Dis 2007;50:1-4.

18 Zarbock A, Schmidt C, Van Aken H, Wempe C, Martens S, Zahn PK, Wolf B, Goebel U, Schwer CI, Rosenberger P, Haeberle H, Görlich D, Kellum JA, Meersch M; RenalRIPC Investigators: Effect of remote ischemic preconditioning on kidney injury among high-risk patients undergoing cardiac surgery: a randomized clinical trial. JAMA 2015; 313:2133-2141.

19 Endre ZH, Walker RJ, Pickering JW, Shaw GM, Frampton CM, Henderson SJ, Hutchison R, Mehrtens JE, Robinson JM, Schollum JB, Westhuyzen J, Celi LA, McGinley RJ, Campbell IJ, George PM: Early intervention with erythropoietin does not affect the outcome of acute kidney injury (the EARLYARF trial). Kidney Int 2010;77:1020-1030.

20 Pickering JW, Endre ZH: Secondary prevention of acute kidney injury. Curr Opin Crit Care 2009;15:488-497.

21 Bellomo R, Bonventre J, Macias W, Pinsky M: Management of early acute renal failure: focus on post-injury prevention. Curr Opin Crit Care 2005; 11:542-547.

22 Zarbock A, Kellum JA, Schmidt C, et al: Effect of early vs delayed initiation of renal replacement therapy on mortality in critically ill patients with acute kidney injury: the ELAIN randomized clinical trial. JAMA 2016;315: 2190-2199.

23 Venkataraman R, Kellum JA: Prevention of acute renal failure. Chest 2007;131:300-308.

24 Ostermann M, Kashani K: Biomarkers for acute kidney injury: where are we now? ICU Manage Pract 2016;16:92-94.

25 Bedford M, Stevens P, Coulton S, Billings J, Farr M, Wheeler T, Kalli M, Mottishaw T, Farmer C: Development of risk models for the prediction of new or worsening acute kidney injury on or during hospital admission: a cohort and nested study. Health Service Delivery Res $2016 ; 4$

26 Mehran R, Aymong ED, Nikolsky E, Lasic Z, Iakovou I, Fahy M, Mintz GS, Lansky AJ, Moses JW, Stone GW, Leon MB, Dangas G: A simple risk score for prediction of contrastinduced nephropathy after percutaneous coronary intervention: development and initial validation. J Am Coll Cardiol 2004;44:13931399.
27 Palomba H, de Castro I, Neto AL, Lage S, Yu L: Acute kidney injury prediction following elective cardiac surgery: AKICS score. Kidney Int 2007;72:624-631.

28 Zappitelli M: Preoperative prediction of acute kidney injury - from clinical scores to biomarkers. Pediatr Nephrol 2013;28:11731182.

29 Chawla LS, Davison DL, Brasha-Mitchell E, Koyner JL, Arthur JM, Shaw AD, Tumlin JA, Trevino SA, Kimmel PL, Seneff MG: Development and standardization of a furosemide stress test to predict the severity of acute kidney injury. Crit Care 2013;17:R207.

30 Koyner JL, Davison DL, Brasha-Mitchell E, Chalikonda DM, Arthur JM, Shaw AD, Tumlin JA, Trevino SA, Bennett MR, Kimmel PL, Seneff MG, Chawla LS: Furosemide stress test and biomarkers for the prediction of AKI severity. J Am Soc Nephrol 2015;26:2023-2031.

31 Goldstein SL, Chawla LS: Renal angina. Clin J Am Soc Nephrol 2010;5:943-949.

32 Basu RK, Zappitelli M, Brunner L, Wang Y, Wong HR, Chawla LS, Wheeler DS, Goldstein SL: Derivation and validation of the renal angina index to improve the prediction of acute kidney injury in critically ill children. Kidney Int 2014;85:659-667.

33 Leedahl DD, Frazee EN, Schramm GE, Dierkhising RA, Bergstralh EJ, Chawla LS, Kashani KB: Derivation of urine output thresholds that identify a very high risk of AKI in patients with septic shock. Clin J Am Soc Nephrol 2014;9:1168-1174.

34 Lenert L, Sundwall DN: Public health surveillance and meaningful use regulations: a crisis of opportunity. Am J Public Health 2012; 102:e1-e7.

35 Electronic Health Records (EHR) Incentive Programs: Centers for Medicare and Medicaid Services (CMS), 2011.

36 Hoste EA, Kashani K, Gibney N, Wilson FP, Ronco C, Goldstein SL, Kellum JA, Bagshaw SM: Impact of electronic-alerting of acute kidney injury: workgroup statements from the 15(th) ADQI consensus conference. Can J Kidney Health Dis 2016;3:10.

37 Rind DM, Safran C, Phillips RS, Wang Q, Calkins DR, Delbanco TL, Bleich HL, Slack WV: Effect of computer-based alerts on the treatment and outcomes of hospitalized patients. Arch Intern Med 1994;154:1511-1517.

38 Goldstein SL, Kirkendall E, Nguyen $\mathrm{H}$, Schaffzin JK, Bucuvalas J, Bracke T, Seid M, Ashby M, Foertmeyer N, Brunner L, Lesko A, Barclay C, Lannon C, Muething S: Electronic health record identification of nephrotoxin exposure and associated acute kidney injury. Pediatrics 2013;132:e756-e767.
39 Colpaert K, Hoste EA, Steurbaut K, Benoit D, Van Hoecke S, De Turck F, Decruyenaere J: Impact of real-time electronic alerting of acute kidney injury on therapeutic intervention and progression of RIFLE class. Crit Care Med 2012;40:1164-1170.

40 Cho A, Lee JE, Yoon JY, Jang HR, Huh W, Kim YG, Kim DJ, Oh HY: Effect of an electronic alert on risk of contrast-induced acute kidney injury in hospitalized patients undergoing computed tomography. Am J Kidney Dis 2012;60:74-81.

41 Kolhe NV, Staples D, Reilly T, Merrison D, McIntyre CW, Fluck RJ, Selby NM, Taal MW: Impact of compliance with a care bundle on acute kidney injury outcomes: a prospective observational study. PLoS One 2015;10: e0132279.

42 Sellier E, Colombet I, Sabatier B, Breton G Nies J, Zapletal E, Arlet JB, Somme D, Durieux P: Effect of alerts for drug dosage adjustment in inpatients with renal insufficiency. J Am Med Inform Assoc 2009;16:203-210.

43 Thomas ME, Sitch A, Baharani J, Dowswell G: Earlier intervention for acute kidney injury: evaluation of an outreach service and a longterm follow-up. Nephrol Dial Transplant 2015;30:239-244.

44 Wilson FP, Shashaty M, Testani J, Aqeel I, Borovskiy Y, Ellenberg SS, Feldman HI, Fernandez H, Gitelman Y, Lin J, Negoianu D, Parikh CR, Reese PP, Urbani R, Fuchs B: Automated, electronic alerts for acute kidney injury: a single-blind, parallel-group, randomised controlled trial. Lancet 2015;385: 1966-1974.

45 Oh J, Bia JR, Ubaid-Ullah M, Testani JM, Wilson FP: Provider acceptance of an automated electronic alert for acute kidney injury. Clin Kidney J 2016;9:567-571.

46 Mehta RL, McDonald B, Gabbai F, Pahl M, Farkas A, Pascual MT, Zhuang S, Kaplan RM, Chertow GM: Nephrology consultation in acute renal failure: does timing matter? Am J Med 2002;113:456-461.

47 Costa e Silva VT, Liaño F, Muriel A, Díez R, de Castro I, Yu L: Nephrology referral and outcomes in critically ill acute kidney injury patients. PLoS One 2013;8:e70482.

48 Meier P, Bonfils RM, Vogt B, Burnand B, Burnier M: Referral patterns and outcomes in noncritically ill patients with hospital-acquired acute kidney injury. Clin J Am Soc Nephrol 2011;6:2215-2225. 